Richard Benson

worked as recreation development officer at Fremantle City Council for over 3 years until October 2001. While there he had a broad role in recreation that included policy writing, strategic planning and programme development. Richard has a masters degree in parks, recreation and tourism management from Lincoln University in New Zealand. Recently, Richard moved back to New Zealand to take up the position as manager of the Community Trust Sports Centre in Timaru.

Keywords:

local government, recreation planning, sporting heritage, sport

Richard Benson

Manager

Community Trust Sports Centre

Morgans Road

PO BOX 634

Timaru

New Zealand

Tel: +6436860461

Fax: +6436860752

E-mail: sport@timaru.com

\section{Preserving a community's sporting heritage through local government recreation planning}

\author{
Richard Benson \\ Received (in revised form): 21 January 2002
}

\begin{abstract}
Fremantle City Council (FCC) is a local government authority located in Fremantle, a historically significant part of south-west Australia. One of the FCC's major functions is to plan for the future of the area, including responding to the recreation and sporting needs of the Fremantle community.

The FCC completed a five-year recreation policy and strategy in December 2000, with the finished document identifying and addressing a number of themes, issues and problems about recreation and sport important to the Fremantle community. Following a process of community consultation the final document provides a pragmatic and applied approach to meeting the recreation and sporting needs of the community.

A notable theme to emerge during the gathering of information centred round Fremantle's extensive sporting heritage and the strong desire for the FCC to support and enhance this legacy. Sport gave the port city its early identity, engendering community spirit and friendly but serious rivalry between it and other neighbouring communities. However, the prominence of sport in the Fremantle community has somewhat lessened in recent times due to a variety of reasons. The city is now recognised more for its cultural festivals, its artistic endeavours from both community and professional artisans, its beaches and the South Terrace cappuccino strip.

Through its recreation policy and strategy, the FCC has been able to respond to the problem in a variety of ways. Initiatives identified include a sporting heritage museum, an oral history of sport to be linked closely to Fremantle's social history, continued support for the Fremantle Sporting Wall of Fame project and improvements to the FCC's current level of support for sport, particularly at the junior level.
\end{abstract}

\section{INTRODUCTION}

Fremantle is located in the south-west corner of Australia. It is bounded on two sides by the Indian Ocean and the Swan River and is Western Australia's major commercial port. Regarded as Western Australia's second city after Perth, Fremantle is a major regional centre for cultural and economic activity. The population of Fremantle is around 24,000 and is expected to remain at this level for the next 20 years or so. 


\section{Strong identity}

\section{Community representation}

The Fremantle area has a strong identity based on its part in many significant and historical events and happenings. The area was an important meeting place for Aboriginal people before European settlement because of its location near the ocean. The close proximity of both the Swan River and the Indian Ocean have also seen it develop as a working port, a base for the fishing industry and after the Second World War as the western gateway to Australia. Added to this is the large number of heritage buildings such as the Round House, the oldest remaining building in Western Australia and used originally as a gaol. ${ }^{1}$

As the local government authority for the area, Fremantle City Council (FCC) is responsible for a large array of functions. These include delivering services such as rubbish collection, road building and maintenance and library services. The FCC is also responsible for urban design, regulating building development and planning for Fremantle's future direction, including planning for recreation and the management of its reserves, sports fields, sports facilities and recreation centres.

\section{RECREATION PLANNING PROCESS}

The process of preparing a recreation policy and strategy provided numerous opportunities for participation and was documented in a recreation planning brief prepared in conjunction with the Fremantle Sports and Recreation Advisory Committee (FSRAC). The FSRAC is an FCC-appointed advisory committee made up of elected members and representatives from sport and recreation groups and the wider community. The FSRAC was closely involved in the planning process, with all policies and strategies going before them for recommendation to the FCC. The FSRAC had previous to this been actively involved in the preparation of several policy documents, including the 1992 five-year sport and recreation plan.

The brief outlined the type of input sought and the groups and individuals that would be approached. Two independently facilitated focus groups, one involving the FSRAC and the other a group representing 12 different sports, were held first, followed by a sports club survey, a telephone survey of Fremantle residents and interviews with sporting goods retailers. Supplementing the above research was a literature review and one on one meetings with selected staff of the FCC. Because no one method of research was considered suitable in all circumstances, a variety of research methods were utilised.

The FSRAC acted as a filter for all the information received as well as bringing their own expertise and points of view to the process. Many of the adopted policies and strategies were identified as potential solutions following each of the information gathering activities. Broad criteria were established which suggested that all responses be realistic and achievable and in the end acceptable to elected members of the FCC as they would be adopting the document on behalf of the Fremantle community. For example, 


\section{Annual review}

\section{Opinions canvassed}

potential solutions requiring a large capital investment were replaced with responses that would investigate that particular issue further. Resources were therefore used to establish the feasibility of going ahead with a large capital investment.

For clarity the Fremantle recreation policy and plan is split into three parts, covering the areas of recreation and sports facilities, the delivery of recreation and sports programmes and activities and services and support for recreation and sport. This approach reflected the preference of the author to have a document that presented a broad-based and integrated response to recreation and sport problems in Fremantle. For example, levels of sports field maintenance require close liaison with user groups, making the need for coordination and communication important. The document also combines both policies and strategies, and in doing so creates a practical reference point for addressing recreation and sport problems and identifying possible solutions.

The appropriateness and suitability of the policies and strategies will be reviewed annually, with a major review and replication of various research activities, such as the telephone survey, taking place every five years. Both time frames permit a defined period for the polices and strategies to be tested further against community opinion, a changing political agenda or altered priorities.

\section{LOCAL GOVERNMENT AND RECREATION PLANNING}

The need for recreation planning and policy making has taken on greater significance over the past ten or so years at all three levels of government in Australia. Federal and state governments provide support to local government in the form of publications, ${ }^{2}$ seminars, consultants to assist during the planning process and financial assistance for the preparation of plans and policies. A planned approach to recreation and sport encourages sound investment and ensures resources are spread across a range of clearly identified priorities and activities.

For local government authorities, the planning process can take on additional meaning because it provides an opportunity to get close to the community and canvass opinion and comment. Consultation with the community is the basis for constructing plans and strategies and the means to develop networks and a positive working relationship with individuals, groups and the wider community. ${ }^{3}$

When planning for recreation, local government considers a wide range of stakeholder opinion whose interests and own policies can influence the direction taken. The Western Australian Ministry of Sport and Recreation and the Australian Sports Commission provided some level of direction for the FCC's own recreation future, but the local community readily indicated important aspects and concerns for sport and recreation in Fremantle. They included continued access to river foreshore and beaches, development of indoor recreation centres, partnering schools in dual use facilities to 
Characteristics of sporting heritage expand sport and recreation opportunities and the provision of open space.

There was also strong support for the traditional sports delivery system, which consists of local clubs providing sporting opportunities and competitions in the community. The concern lay in the fact that many sports clubs are struggling to remain active, with difficulties including declining memberships, falling revenues and stricter drink-driving laws impacting on those which rely on bar takings. ${ }^{4}$

\section{UNDERSTANDING FREMANTLE'S SPORTING HERITAGE}

No attempt was made to define sporting heritage. However, sport was defined as being activity oriented, characterised by some level of physical exertion, certain skills being necessary to take part, the activity being bounded by rules and sport being hierarchical and competitive. In combination with the definition for sport the understanding of what sporting heritage means to Fremantle's community evolved and is best characterised in the following excerpt from the Recreation Policy and Strategy.

'Fremantle has a sporting and recreation heritage that is the pride of the local community and the envy of other communities. A number of local clubs have been in existence in various guises for around 100 years while others are much younger.

Fremantle's sports heritage was best exemplified at the Inaugural Induction into the Fremantle Sporting Wall of Fame. Held in June 1998, the intention of the ceremony was to honour local sportswomen and sportsmen during the past one hundred years or so. There is a strong desire to continue with the Wall of Fame project, so that it goes on to fulfil its other objectives of educating the community and recognising and honouring sporting achievement.

However, concerns have been expressed that this heritage could be lost or diminished as the nature of the sport and recreation environment changes. Recreation organisations and sports clubs are continually searching for participants, or contemplating moving to alternative but better equipped venues. Many endeavour to retain teams at the highest possible level of competition while attempting to also foster the activity at the grass "roots level".5

The 1998 Fremantle Sporting Wall of Fame event took the sporting past and brought it into the future, and in doing so became the building block to safeguard Fremantle's sporting heritage. The wider Fremantle community were introduced to an extensive sporting heritage and memories that previously had belonged 
almost exclusively to local sports clubs ${ }^{6}$ and various individual sports people and their families.

The FSRAC was the initiator and driver behind the Sporting Wall of Fame. The FSRAC reasoned that Fremantle had a unique sporting heritage in many ways in Western Australia. For example, over a 100-year period Fremantle produced a large number of Australian and state representatives in all manner of sports, including Australian rules football, softball, basketball, yachting, cricket and badminton. Fremantle's heritage was not a result of any one significant event but a rich amalgam of happenings and performances over a long time period.

With the Fremantle Sporting Wall of Fame acting as an important catalyst, policy and action responses for sporting heritage in the recreation policy and strategy were formulated. The FSRAC played an important role in this process not just because of their official position as the community's representatives for sport and recreation. The FSRAC had a strong sense of ownership of the Fremantle Sporting Wall of Fame project and wished to establish priorities for the future.

\section{Significant role of sport}

\section{THE SPORTING HERITAGE OF FREMANTLE AT A GLANCE}

Fremantle played a significant role in the development of football in the state as early as 1885 , when a meeting of interested people at the Cleopatra Hotel adopted the new code of Australian rules. The Fremantle Football Club, which was established as a result of the meeting, went on to be the dominant team during the game's early years in Western Australia. The game of Australian rules football has remained a visible part of Fremantle's sporting scene for over 100 years and culminated with the entry of the Fremantle Dockers into the Australian Football League (AFL) in 1995.

The popularity of football in Fremantle was supported by the local council, which readily provided resources to develop facilities and various infrastructure. As early as 1897 a significant and now historical grandstand, the Victoria Pavilion, was completed by FCC at a cost of $£ 3,650 .^{7}$ Two years earlier, the first official football game had been played at the same venue, the Fremantle Oval.

Footballers also dominate the list of 38 inductees of the Fremantle Sporting Wall of Fame, a project whose aim is to recognise and acknowledge publicly the sporting achievements of Fremantle sportswomen and sportsmen. Australian rules footballers include W. J. 'Nipper' Truscott, who is also one of 12 inaugural members of the Western Australian Hall of Champions. ${ }^{8}$ More commonly known footballing names are John Worsfold, captain of the dual AFL premiership-winning team, the West Coast Eagles and Brownlow Medallist Brad Hardie.

There are a further 16 sports represented in the Wall of Fame, indicating the large variety of organised sporting activity in Fremantle over the past 100 or so years. Inductees have represented either Australia or Western Australia in sports as diverse as 
All-Australian game

\section{Cultural development}

basketball, golf, badminton, cricket, lawn bowls and tennis. Surprisingly, there are no 'yachties' inducted into the Fremantle Sporting Wall of Fame, given the dominance of sailing, the presence of numerous marine industries in the community and Fremantle's hosting of the America's Cup in the mid-1980s.

While the above snapshot suggests a significant sporting heritage, the information presented in the next section suggests that various social, economic and demographic changes have combined to reduce the importance of sport to the Fremantle community. Some of the changes are recent and others, such as changing FCC spending priorities, have been occurring for 50 years or more.

\section{CHANGES TO THE FREMANTLE COMMUNITY}

The forces of change in a community and more specifically sport participation are numerous and dynamic. ${ }^{9}$ The following discussion identifies some broad trends and the probable outcomes of those trends in relation to sport in the Fremantle community.

The influence of migrants from Great Britain during the early period of Fremantle's establishment in the middle of the 19th century helped create a range of sports clubs and activities reminiscent of the practices migrants left behind. By the end of the century clubs had formed for sports such as cricket, sailing, tennis and lawn bowls. However, it was football, the all-Australian game, that flourished, with no fewer than seven teams or clubs at various times in and around Fremantle up until the 1920s. The clubs were a mix of professional and amateur, with some clubs able to attract players from Victoria in the east with tempting offers. ${ }^{10}$

The FCC's involvement with sport began at around the turn of the century. The Fremantle Oval had been vested in the FCC by order of the governor in executive council in 1894 and the FCC set about upgrading the reserve at a cost of $£ 640 .{ }^{11}$ Reserve land was also given over to clubs to lease, while funding was sought and received from the FCC for various sporting projects. Land for recreation and sporting purposes was either purchased by the FCC or vested in the FCC by the government of the day. Whimpress ${ }^{12}$ suggests the historical development of sport is a good indicator of the social priorities of a community, and this was true for Fremantle from the time of early European settlement until perhaps the 1970s. Since this time sport, as the major expression of Fremantle's culture, has remained prominent but the FCC's resourcing priorities have changed.

The FCC began to involve itself in cultural development with the establishment of the free lending library in 1949. The cultural development activities of the FCC have gone on to encompass a large array of initiatives, from arts programmes and festivals through to supporting the development of arts infrastructure. In the 1970s the FCC began also to take a lead role in the preservation and restoration of heritage buildings, many in conjunction with the state government. ${ }^{13}$ Another major thrust over the past 20 years is 
Immigration

\section{Economy}

\section{Popular activities}

the FCC's role in social welfare activities such as aged care, domestic violence and children's day care.

Immigration to Australia following the Second World War meant Fremantle has developed into a multicultural community. Current figures indicate that one-third of Fremantle's residents were born overseas. Migrants from many different countries in Europe brought with them their own cultural values and readily express them in the Fremantle community. A good example of this is the Italian café influence along the cappuccino strip. Sport has also benefited from this influx, with the greatest growth being in soccer. Over the past 25 years four soccer clubs have been established, most along ethnic origins.

The strength of Fremantle's economy has traditionally focused on the port and port-related industries and commercial services. However, over the last decade some sectors in the local economy have declined in importance while others, such as tourism, have experienced considerable growth. Activities such as festivals, heritage tourism and the Fremantle dining experience are now major attractions for visitors and are promoted accordingly. Given this change various groups such as local residents, tourists, the labour force and day trippers contribute significantly to the Fremantle economy, with a total aggregate spending of $\$ 435$ million annually. ${ }^{14}$

Changes to the Fremantle community and broader social and economic changes have also altered the way people take part in sport and recreation. A recent survey of 400 Fremantle residents aged 15 years and over established some baseline data for residents of Fremantle. The results identify the most popular activities participated in during the past month. ${ }^{15}$ Table 1 identifies the 11 most popular activities undertaken away from home in the past month, with the majority able to be undertaken without necessarily belonging to a club or any formal organised grouping.

Generally the popular activities are reflective of other similar participation surveys. ${ }^{16}$ Significantly for Fremantle, Australian rules football does not feature in the list but soccer does. This could be because of the survey's timing in November, but there could be
Table I: Most popular activities

\begin{tabular}{lc}
\hline Activity & \% (Total) \\
\hline Walking & 44 \\
Swimming & 29 \\
Cycling & 15 \\
Gym & 8 \\
Beach activities & 8 \\
Fishing & 6 \\
Tennis & 5 \\
Running/jogging & 4 \\
Sailing/yachting & 4 \\
Golf & 4 \\
Soccer & 3 \\
\hline
\end{tabular}


various other reasons. Soccer may feature because of the influence of Fremantle's Western European migrants or the success of the local National Soccer League club, Perth Glory, who play their competition matches between October and March, during the summer months. While participation in Australian rules football remains high in relation to most other sports, ${ }^{17}$ there has not been major success at a national level for Perth-based football teams since 1994.

Although providing baseline data and being the first of this type of survey in Fremantle, the results tend to supplement other information available in Australia. The Western Australian Ministry of Sport and Recreation ${ }^{18}$ and a recreation plan prepared for the South West Regional Recreation Advisory Group ${ }^{19}$ indicate levels of participation in various organised sports are declining. This is coupled with the traditional sports delivery system facing difficulties such as decreasing membership, gaining, training and retaining volunteers, youth participation and the growth in competition from commercial sports centres which offer the 'pay as you play' choice.

The point should be made that overall rates of participation for organised sport and casual recreation activities may not have changed significantly over time but the importance of casual participation over the other has. The move towards casual participation reflects some broad community trends such as longer working hours, higher disposable incomes for some and less commitment towards volunteering.

In summary, changes that have occurred in Fremantle since European settlement have meant changing emphasis and priority for organised sport in the community. Participation and support for traditional sports such as Australian rules football has changed as different values have influenced the community. In part the influence of FCC's priorities has had an impact, while other fundamentals such as changes to employment patterns, immigration and shifting to a service economy have left a lasting impression.

\section{POLICY AND STRATEGY RESPONSES FROM THE CITY OF FREMANTLE}

The FCC's response to the issue of sporting heritage and its preservation involves a number of policies, strategies and actions. These have been shaped by FCC's stated vision in the recreation policy and strategy, which is:

\section{'Fremantle has a sustainable, yet diverse, resource of recreation and sporting facilities, programmes and services, catering for a wide variety of individuals and groups, while ensuring quality service and user safety. ${ }^{20}$}

The vision is in keeping with local government's broad mandate in relation to service provision and working with local communities in 


\section{Support for local sport}

\section{Changed expectations}

order to meet their many needs. However, the vision introduces the idea of sustainability. In this context sustainability is taken to mean that something will last because it was undertaken with a clear understanding of its need and its costs, both present and ongoing. The reality is that policy and strategies with financial implications may only occur when supported financially by the FCC, most likely in partnership with other interest groups.

Notwithstanding the above, policies and strategies in support of the traditional sports delivery system are numerous. By supporting the traditional sports delivery system at the local level, the FCC is endeavouring to strengthen clubs' ability to survive and endure. However, where funding assistance is offered it comes with strings attached. The main one is that sports clubs will need to supply information about their club in the form of annual reports and annual audited accounts. The intention is to use the information as the basis for questioning the club, if necessary, about the way it operates and functions. Early identification of problems means some measured level of intervention can be put in place that will assist. The funding pool is also contestable.

Sports clubs may also request other more general support from the FCC. This will take the form of information and guidance with needs assessments and feasibility studies, policy development and strategic planning, club development and management, including training opportunities for volunteers and funding sources, recreation opportunities and networking. Once again, the policies are conceived to aid the club to remain viable.

State sports associations also have a role to play. They must be able to provide the FCC with reasonable requests for information and assistance, such as memberships and facilities of local clubs should any club show signs of being under threat. The FCC's role is to act as a coordinator or advocate for the community and the club in particular, and to work to identify potential solutions and options. Examined in the context of the often indifferent relationship between local sports clubs and governing sports bodies, the responsibility being taken by the FCC is an important one and must be encouraged.

The policy direction outlined above is aimed at assisting the traditional sports structure and also suggests the $\mathrm{FCC}$ will have a variety of roles to fulfil in supporting this. The FCC has an expectation that clubs must raise their game in order to meet new challenges as societal and community change continues to impact on them. They must become more businesslike rather than acting on 'gut feeling' or doing what has happened in the past. This will of course provide one of the desired outcomes from the recreation policy and strategy, which is to improve service delivery to aid the efficient and effective use of the FCC's resources.

Not all policy is in the sports delivery area - it also includes recreation and sports facilities. In the city's 27 square kilometres there are over 230 hectares of public reserves and open space ${ }^{21}$ and 
Management plans

\section{Five-year plan}

an FCC-owned swimming pool and single court recreation centre. The management of the community's sports assets is an area in which the emphasis shifts to the FCC to improve on its current performance in areas such as policy development, planning for asset creation and asset maintenance.

Specifically policies indicate that management plans are necessary for all sports reserves. Management plans will outline the FCC's general intentions for use, development and maintenance and be an ongoing management tool. A framework called a sporting facility classification system will also assist the FCC. The system will place each sports facility in a hierarchy from local up to regional and will help to identify the function and therefore the type and scale of development and the level of resourcing necessary at the facility. For example, a regional facility important to the city will also have some relevance as a state facility and may have been developed by a state sports association rather than a local club. ${ }^{22}$

The policies set the broad framework from which the strategies and actions listed in Table 2 were identified. They include a mixture of new strategies and actions and others which formalise existing practice, giving some sense of importance and continuity. The designations of strategy and action were used for convenience and to help order a range of often complex information. To elaborate further, the five-year plan contains strategic objectives with one or a number of strategies included and then an action or a number of actions under each strategy. There are 13 strategic objectives under three broad areas, which are recreation and sports facilities, the delivery of recreation and sports programmes and activities and services and support for recreation and sport.

The first three actions listed in Table 2 are directly related to preserving and acknowledging the Fremantle sporting traditions of the past. In combination, they ensure comprehensive coverage of the sporting heritage of Fremantle and represent very real opportunities for the wider community also to acknowledge the importance of sport to Fremantle. A further step in this process would be to use the inductees from the Wall of Fame as role models for young and old sports participants alike. Looking to the future, a new funding scheme to encourage sport and recreation participation will be introduced. Research undertaken during the planning process suggested that sports clubs need additional financial support for minor capital works and other projects such as volunteer training. Eligible projects include junior sport development, recruiting and promotion programmes, training and support for volunteers and minor capital works, such as access for people with disabilities and installation of training lights.

Because of the close association with the community and an understanding of local needs, local government authorities are best placed to give support for minor capital projects and manage a scheme that facilitates this - hence the action to advocate for funds and delegation of decision making from the Western 
Table 2: Sporting heritage actions and strategies

\begin{tabular}{|c|c|c|}
\hline Strategy/action & New/existing & $\begin{array}{l}\text { Year of } \\
\text { implementation }\end{array}$ \\
\hline Wall of Fame facility/structure is designed and constructed & New & Years 2 and 3 \\
\hline Develop an oral history of 'port and sport' & New & Years 4 and 5 \\
\hline Third Wall of Fame induction & Existing & Year 4 \\
\hline $\begin{array}{l}\text { Sport and recreation participation scheme (with funding the } \\
\text { equivalent to } 50 \text { cents per head of usual resident population) }\end{array}$ & New & Years 1 to 5 \\
\hline $\begin{array}{l}\text { Advocate for additional funds for distribution and devolution of } \\
\text { decision making from the Department of Sport and } \\
\text { Recreation }\end{array}$ & New & Years 1 to 5 \\
\hline $\begin{array}{l}\text { Financial grants for lessees where the public retains access } \\
\text { privileges to leased areas, including developing criteria }\end{array}$ & New & Years 1 to 5 \\
\hline Annual survey of sports clubs & New & Years 1 to 5 \\
\hline Preparation of a junior sport policy & New & Year 2 \\
\hline Adopt the sporting facility classification system & New & Year 1 \\
\hline Preparation of a sportsfield management plan & New & Year 2 \\
\hline $\begin{array}{l}\text { Prepare and review a five-year asset creation and improvement } \\
\text { programme for open space }\end{array}$ & New & Years 2 to 4 \\
\hline Join the Active Australia Local Government Network & New & Year 1 \\
\hline Regular newsletter to sports clubs & Existing & Years 1 to 5 \\
\hline Fremantle Sports Awards are presented & Existing & Years 1 to 5 \\
\hline Youth Sports Scholarships are presented & Existing & Years 1 to 5 \\
\hline $\begin{array}{l}\text { Regular review of the recreation policy and strategy as well as } \\
\text { other policy documents }\end{array}$ & New & Years 1 to 5 \\
\hline
\end{tabular}

Australian Department of Sport and Recreation to the FCC in these matters.

A further grant funding scheme is also planned. The basis of the scheme is an acknowledgment that because of continued public access there is a cost, in terms of ground maintenance, to sports clubs that lease reserves from the FCC. Lessees pay all the costs of reserve maintenance, despite costs such as vandalism and cleaning up dog excreta generated by the public. The clubs only have exclusive use at times when the area is needed for their use. Funds up to $\$ 2,000$ per annum will be allocated based on several criteria, including proximity of other open space and extent of fencing surrounding the leased area. The FCC and sports clubs have no desire to make sporting reserves exclusive, as there is a fundamental right of access to public lands.

Perhaps the most important of all the strategies is the desire to

\section{Policy output} lift the FCC's output in terms of policy development and plans that manage the FCC's sporting assets. The strategic document that preceded the recreation policy and strategy was conceived in 1992, while the policy on sport was adopted by the FCC in $1985 .^{23}$ Specifically, there is a desire to prepare a number of policies, including one for junior sport. The need for a junior sport policy recognises that many young people drop out of organised sport in their teens for a variety of reasons, including peer pressure and having numerous choices for their recreation. The policy will complement the work already undertaken by the Western Australian Department of Sport and Recreation and state sports associations.

Additional plans will assist the FCC to improve the management 


\section{Facility classification} systems of public reserves and open space, with a particular focus on sports facilities. The sports facility classification system was adopted when the FCC adopted the full recreation policy and strategy. The asset creation and improvement plan will be developed over a period of time, but reserves that play host to organised sports activities will be given first priority. The plan will incorporate a development programme over five years, identify priorities and, give indicative costs and possible sources of finance for the projects. The scale and scope of improvements will be dependent upon a number of considerations, including the facility's position in the sports facility classification system hierarchy.

Other important existing practices will continue. They include the Fremantle Youth Sports Scholarships that are awarded to six talented junior sports people annually for additional coaching or travel to competitions. The Fremantle Sports Awards will also carry on as will the regular production of a newsletter to sports clubs.

\section{CONCLUSIONS}

Following a process of community consultation and review the FCC adopted the recreation policy and plan in December 2000. A significant theme to emerge during the planning process was the sporting heritage of the Fremantle community and how it can best be preserved in a community that has changed in many ways over the past 100 years. The focus on sporting heritage ran parallel to the already strong interest shown by the community in Fremantle's unique history and heritage buildings.

The FSRAC played an important role on behalf of the community. The Sporting Wall of Fame was their original sports heritage project, providing a building block on which to establish policies and strategies for the future of sport in Fremantle. New directions for the FCC encapsulate sports heritage projects, funding programmes, policy development and preparation of strategic plans.

However, for the policies, strategies and actions to be useful and successful they must catch the attention of those organisations that stand to benefit. For some sports clubs it will mean accepting new challenges and embracing change, while for others it may mean cooperating more with other like-minded clubs. All should, though, push the FCC to ensure that the recreation policy and strategy is fully implemented and that Fremantle's sporting heritage carries on for another 100 years.

\section{Acknowledgments}

Grateful acknowledgment is given the FSRAC, which was instrumental in guiding and assisting with the preparation of the Fremantle recreation policy and strategy. Thanks also to the Western Australian Department of Sport and Recreation for their financial assistance and Adrian Jarvis for additional research. 


\section{References}

1. Website www.freofocus.com.au/about

2. Australian Sports Commission (1997) 'Active Australia - A National Participation Framework', Australian Sports Commission, Canberra; Western Australian Sport and Recreation Council (1999) 'Strategic Directions for Western Australian Sport and Recreation (1999-2002)', Western Australian Sport and Recreation Council, Western Australia; Ministry of Sport and Recreation (1997) 'Recreation Planning Guide', Ministry of Sport and Recreation, Western Australia.

3. Fremantle City Council (1999) 'Our Place: City of Fremantle Cultural Policy and Plan', FCC, Fremantle.

4. Fremantle City Council (2001) 'Recreation Policy and Strategy', FCC Fremantle.

5. Ref. 4 above, p. 5.

6. Cahill, T. (2001) 'Fremantle's Sporting Heritage', FCC, Fremantle.

7. Ewers, John K. (1971) 'The Western Gateway: A History of Fremantle', 2nd edn, University of Western Australia, Nedlands, WA.

8. Western Australian Institute of Sport (2000) 'Western Australian Hall of Champions', Western Australian Institute of Sport,Western Australia.

9. Benson, R. J. (1997) 'Leisure and Rural Communities - A Case Study of Needs and Attitudes in Waipu, New Zealand'. Lincoln University: Canterbury, New Zealand; Cushman, G. (1991) 'National and International Leisure Trends and Issues', Lincoln University, Canterbury, New Zealand: Western Australian Sport and Recreation Council, ref. 2 above

10. Heinrichs, D. (1947) The Jubilee Book of the East Fremantle Football Club, Patersons Printing Press, Perth.

11. Ewers, ref. 7 above.

12. Whimpress, B. (1992) 'The value of facts in sports history', Journal of the Australian Society for Sports History, Vol. 9, No. 1, pp. 2-15.

13. Fremantle City Council, ref. 3 above.

14. Fremantle City Council (1998) 'Community Profile', FCC, Fremantle.

15. Advantage Communications (1999) 'Summary Report City of Fremantle Sport and Recreation Survey', Advantage Communications, Perth.

16. Veal, T. (2001) 'Participation in sport', Australian Parks and Leisure Journal, Vol. 4, No. 1 , pp. $14-15$

17. Ministry of Sport and Recreation (1997) 'Status of Sport in Western Australia 1996', Ministry of Sport and Recreation and Western Australian Government, West Australia.

18. Ibid.

19. BSD Consultants (1999) 'South West Regional Recreation Advisory Group Regional Sport and Recreation Plan', South West Regional Recreation Advisory Group, Perth.

20. FCC, ref. 4 above, p. 3

21. Fremantle City Council (1999) 'Greening Fremantle, Towards a Green Plan - A Discussion Paper', FCC, Fremantle.

22. FCC, ref. 4 above, p. 3 .

23. Ibid. 